\title{
De Winters modified electrocardiogram pattern
}

\author{
R. C. Rodrigues ${ }^{1} \cdot$ S. Gomes ${ }^{1} \cdot$ A. Drumond ${ }^{1}$ D. Pereira ${ }^{1}$
}

Published online: 14 April 2016

(c) The Author(s) 2016. This article is available at SpringerLink with Open Access

A 59-year-old patient with a family history of coronary artery disease and no other risk factors arrived at the emergency department with typical angina chest pain lasting for 60 minutes. The admission electrocardiogram showed $1 \mathrm{~mm}$ upsloping ST-segment depression at the $\mathrm{J}$ point in leads V3-V6 without peaked T waves (Fig. 1a). The patient underwent primary percutaneous transluminal coronary angioplasty where a kissing ostium was found and proximal anterior descending artery (LAD) occlusion was identified and stented with a drug-eluting stent (Fig. 1b), with successful reperfusion. The patient's stay in hospital was uneventful.

This patient displayed a typical upsloping ST-segment depression but without typical peaked T-waves or aVR STsegment elevation, which is usually associated with a characteristic electrocardiogram pattern first described by De Winters [1] and associated to proximal LAD occlusion. The non-recognition of these unusual STEMI equivalent patterns leads to a higher reperfusion time and is associated with worse outcomes [2, 3].

Open Access. This article is distributed under the terms of the Creative Commons Attribution 4.0 International License (http:// creativecommons.org/licenses/by/4.0/), which permits unrestricted use, distribution, and reproduction in any medium, provided you give appropriate credit to the original author(s) and the source, provide a link to the Creative Commons license, and indicate if changes were made.

R. C. Rodrigues

1 Cardiology Service, Hospital Dr. Nélio Mendonça

Funchal, Portugal

\section{References}

1. De Winter RJ, Verouden NJ, Wellens HJ, et al. A new sign of proximal LAD occlusion. N Engl J Med. 2008;359:2071-2073.

2. Steg G, James SK, Atar D, et al. ESC Guidelines for the management of acute myocardial infarction in patients presenting with STsegment elevation. Euro Heart J. 2012;33:2569-2619.

3. Terkelsen CJ, Sørensen JT, Maeng M, et al. System Delay and Mortality Among Patients With STEMI Treated With Primary Percutaneous Coronary Intervention. JAMA. 2010;304:763-771. 

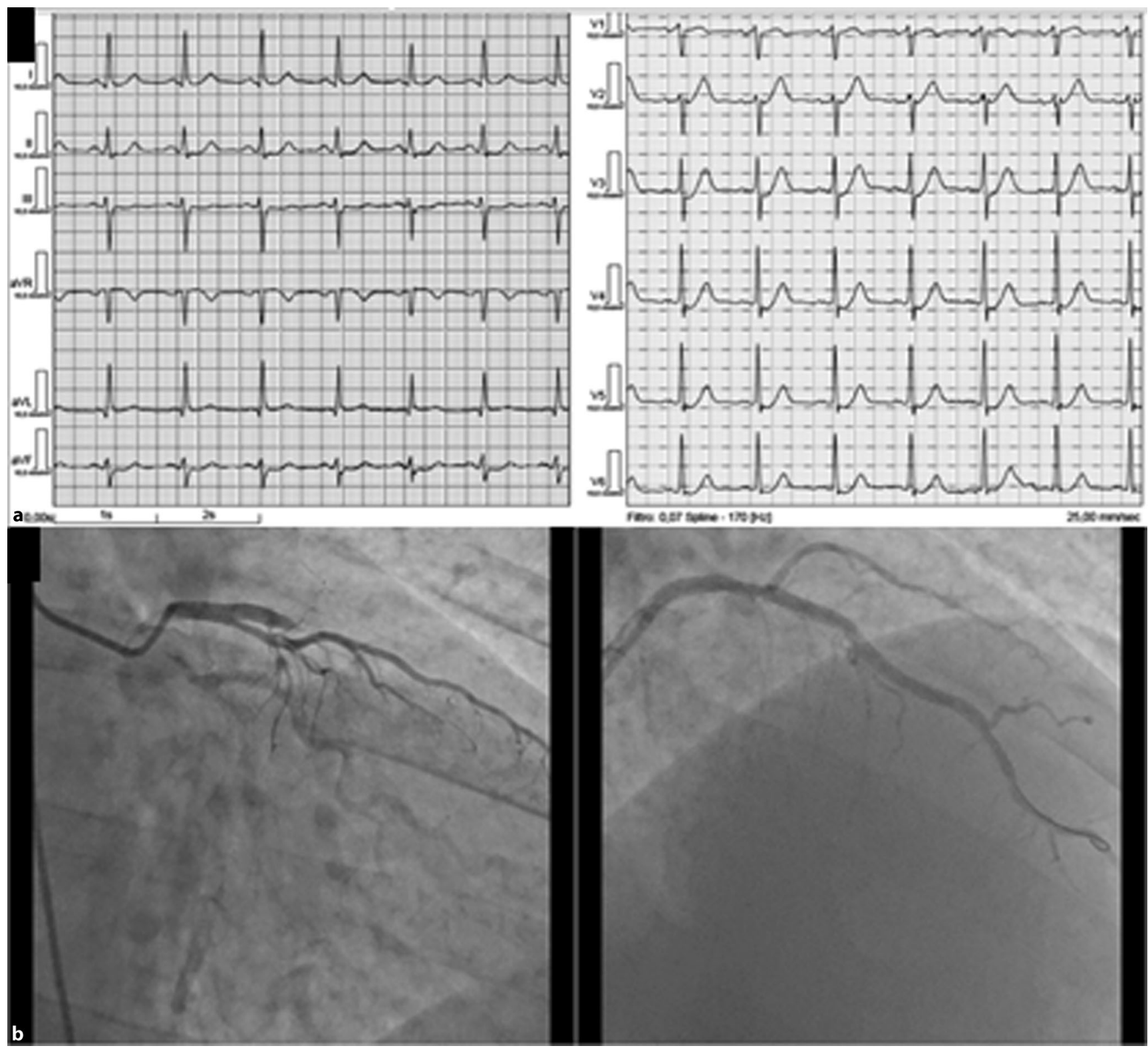

Fig. 1 a 12-lead electrocardiogram showing the "modified de Winters" pattern with $1 \mathrm{~mm}$ upsloping ST-segment depression at the J point in leads V3 to V6; b Angiogram showing a left kissing ostium and occlusion of proximal left anterior descending artery (left) and selective left anterior descending artery catheterization revealing good final result (right) 